\title{
Music and Communism
}

Author(s): C. D. Graham

Source: The Musical Times, Vol. 63, No. 953 (Jul. 1, 1922), pp. 481-482

Published by: Musical Times Publications Ltd.

Stable URL: http://www.jstor.org/stable/908853

Accessed: 01-05-2016 23:10 UTC

Your use of the JSTOR archive indicates your acceptance of the Terms \& Conditions of Use, available at

http://about.jstor.org/terms

JSTOR is a not-for-profit service that helps scholars, researchers, and students discover, use, and build upon a wide range of content in a trusted digital archive. We use information technology and tools to increase productivity and facilitate new forms of scholarship. For more information about JSTOR, please contact support@jstor.org.

Musical Times Publications Ltd. is collaborating with JSTOR to digitize, preserve and extend access to The Musical Times 
are trailing through the hills. And what a flute he has! From some far distant tree he sings, and through the sound of dripping rain and the chatter of bickering sparrows in the blackthorn hedge his song is clearly heard. And what a song he sings! For many years I have kept my ear upon him, and noted his turns of melody. I will not compare him with the nightingale, because my human frailties have interfered with my study of the latter's song. But of birds who sing by day the blackbird is by far the most musical. His song is individual; no two blackbirds sing the same, and yet they seem to be governed by a passing fashion which decides the form but not the details of the song. This year the fashion decides that songs are to be very simple in design, consisting chiefly of a graceful arpeggio, cut rather short, decorated about the close with a delicate shake. My blackbird, therefore, sings a tune of which the following is the chief motive:

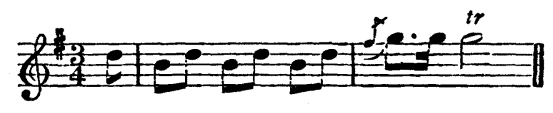

Two years ago the fashion was for much more elaborate tunes, founded upon an arpeggio groundwork but trimmed with chromatic passing-notes. My present little friend's grandfather, the pride of his landlord and the neighbourhood, sang the following motive :

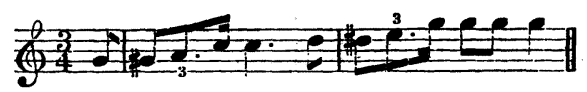

(N.B.-This is transposed down about a fifth.)

This was the principal theme of the song, sung marcato and, I think, un poco nobilmente. After many repetitions of this tune, he would add a cadence possessing great distinction, yet again conforming to the fashion of the year:

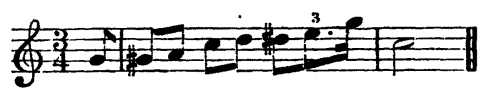

Sometimes he would give a new significance to the phrase by pausing after the $\mathrm{E}$ and flinging out the last two notes with a ring of finality.

Who taught the blackbird to sing in intervals that we can reproduce through our men-made musical notation? Did the blackbird pick his intervals from man, or is there in the depths of nature some guiding principle of sound which birds by chance may stumble on in song? Personally I like the latter view, and I hazard an opinion that though our experimentalists who live in the clangour of the streets may astonish their friends with sophisticated intervals of their own devising, yet for mankind who live in God's own fields the music that will be their happiness and consolation will lie within those worn-out intervals which ring as fresh and beautiful among the trees to-day as they did when God first taught the blackbird, the cuckoo, the thrush, and the nightingale to sing their native tunes in Paradise.

\section{MUSIC AND COMMUNISM}

\section{By C. D. Graham}

In a previous article* some reference was made to the importance attached by the Bolsheviks to what is described as 'cultural propaganda.' There is no need again to enlarge upon the apparent anomaly of a policy which aims at a sane mind at the expense of a sound body. Culture, it seems, still has its uses, although recent associations have placed it on the list of 'tainted' words recently referred to by Mr. A. B. Walkley.

As early as 1918 the Soviet recognised the value of music as an anodyne for "killing care and grief of heart.' Accordingly, in October of that year a body possessing the imposing title of the "Commissariat for Public Enlightenment,' of which Lunascharsky was the head, decreed that music, in common with all other enterprises in Russia, was to be socialised. Among other changes involved, this meant that the conduct of the Conservatoires had to be submitted for approval to specially appointed commissaries instead of being left to the discretion of the governing board of professors. It was decreed also that the students were to be represented on the board by a council of 'elders,' elected from among themselves.

Those who know their Gilbert will remember what happens to a community where 'everybody's somebody.' The scheme, however, seems to have worked well enough in the main, although in some cases it naturally resulted in a good deal of mutual recrimination between the pupils and their nominal chiefs. The reorganization had another comic aspect, for in order to conform still further to the Gilbertian ideas of Communism and the dignity of Labour-and presumably of Art-it was considered advisable to revise nomenclature as well ; thus 'work-shop' was substituted for 'class,' ' master-worker' for 'professor,' 'great assembly' for orchestra, and so forth.

Another astonishing step in the direction of providing music for the million was a decree under which instruction in all music schools was thrown open free of charge. Only in the case of the larger conservatoires was the stipulation made that applicants should display a certain amount of natural aptitude. In March, I919, therefore, all students in the Moscow Conservatoire-to take a typical instance-were subjected to a weeding-out process. Those who failed to reach the qualifying standard were obliged to seek instruction elsewhere. For the rank and file, opportunity for obtaining gratuitous education was afforded by the numerous musical centres which were then springing up all over the country. Many such centres were already in existence, having been founded under the regime of Kerensky for the benefit of the lower classes. Other conservatoires in which high fees were being charged were also 'taken over' by the people, together with all other so-called 'bourgeois' property.

\footnotetext{
* Musical Times, May, rg22.
} 
The curriculum offered by the Soviet is designed on the most up-to-date lines. It is realised, for example, that the average student who takes up an orchestral instrument, and whose qualifications do not mark him out for solo work, will eventually take his place in the ranks of the 'great assemblies.' $\mathrm{He}$ is accordingly put through a progressive course extending over four years, designed with the sole object of fitting him for his vocation. Having acquired a thorough knowledge of the arts and mysteries of his craft by means of lectures and practical adventures among the masterpieces, he is turned out at the end of his course a finished product of intensive culture, and considered capable of dealing faithfully with anything that may be set before him.

There is surely a great deal to be said in favour of a system so practical that it takes into account the fact that not all are born to greatness. Orchestral playing is an art, but it is an art which can be acquired, whereas no amount of training can create an artist in interpretation. But genius will out in any event, and it is improbable that outstanding merit would be neglected under the Bolshevist system. In the meanwhile it would be interesting to know how the communistic idea is shaping in practical operation, and whether, with food at famine prices, the Russians would not cheerfully forego 'culture' in exchange for benefits of a more tangible kind.

\section{INSTRUMENTATION : SOME STRANGE SURVIVALS \\ BY ULRIC DAUBENY}

This paper is not designedly written from the antiquarian stand-point. It attempts to discuss an aspect of orchestral instrumentation, a manner in which brass wind instruments are employed by a certain school of professedly 'modern' composersminor composers, as inevitably they must be, but none the less existent at the present day, and unquestionably, as estimated by themselves, far removed from the 'genuine antique.' How far members of this school are impervious to advances made even so long ago as the later Victorian era, how far they conform to the mediæval in their ideas, how far their case, for adequate appreciation, must be submitted to the antiquarian and folk-lorist, may be left for the individual reader to decide.

To many, the very existence of such a reactionary school must be unsuspected : even the possibility of its survival is a suggestion which will evoke considerable incredulity among all but the initiated few. So it was with the writer, until a chance conversation gave the necessary hint, and brought cohesion to a scattered accumulation of memories which hitherto had been allowed to drift.

It was a student, presumably considered 'advanced,' who gave the clue. Said he, contradicting a remark concerning brass instrumentation :

'You must understand that the French horn and the trumpet are not chromatic. The horn, to a certain degree, is the more chromatic of the two, but with both the natural harmonics only should be used, changing the key of the instrument according to requirements by means of crooks. Notes other than these harmonics, that is to say notes produced by means of valve mechanism, are greatly inferior in timbre, and consequently the experienced composer avoids using them.'

Possibly the wording was less choice, but none the less these amazing notions were testified by a student -a student!-in this year of grace 1922 ! The writer, it must be confessed, was too utterly dumbfounded to reply with a single word. Perhaps also he perceived the uselessness of proffering valuable information gratis, when the poor deluded was doling out good money to be taught such ridiculous old-wives' twaddle. For it is an astounding fact, when realised, that men are actually living who take fees for teaching obsolete nonsense, and young men there are so lacking in common intelligence as to imbibe such 'information,' in the fond delusion that they are learning modern methods of orchestration!

Am I on the track of a solitary and exceptional case? Have I discovered some hoar Methuselah of music, cooped up in a hamlet of the Outer Hebrides? In all seriousness, No. Reawakened memories, for me, confirmed this at the outset, but to make conviction doubly sure, I took the opportunity for examining examples of a certain type of orchestral score-the works, be it understood, of Mus.Bacs. and Mus.Docs., of men still actively engaged in composition. Therein our antediluvians became self-confessed in black and white. The student really proved to be their educated parrot, while their own works stood forth as their criteria, those and the oratorios of old, old Handelyes, and of Mendelssohn, but of no one more juvenile than Mendelssohn. For, to reveal a secret, these prehistorics are to be found among the ranks of those who produce 'modern' oratorios, sacred cantatas, and like works. It is not suggested that the majority of such composers are abnormally behind the times, but the assertions must be reiterated that a certain appreciable percentage are reactionary in the extreme, and that they not only uphold this attitude in their compositions, but also make for its perpetuation by passing on the tradition to their hapless pupils.

Now to formulate the charge, and to reveal the method by which the unfortunate French horn and trumpet are so maltreated. The familiar old harmonic scale is taken :

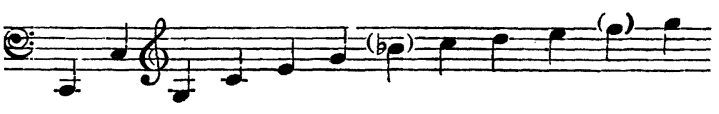

The upper eight or nine notes are allotted to the first horn, and the lower eight or nine notes to the second horn. (The bracketed notes, as 'open harmonics,' are out of tune with tempered harmony, but if a man has only eight or nine notes to play about with, he cannot afford to be too particular, so use these notes he will, however out of tune.) The reactionary then scores his horn parts, drawing only from the harmonic scale, and industriously writing, as the key of his composition varies, 'Change to $\mathrm{E}$,' or 'Change to D.' By the time he has finished he will have scored parts for horns in $B$, horns in $A$, in $G$, in $F$, in $E$, in $E$ flat, in $D$, and in $C$-if not in other keys as well, fondly imagining that the player will come with about a dozen crooks on his arm, with which to juggle at the bidding of the written instruction. What actually transpires is that the 